\title{
Derribando muros: la lectura en pantalla y la docencia universitaria
}

\section{Knocking down walls: on-screen reading and university teaching}

\author{
María Bernarda Torres ${ }^{1}$ \\ bernie.torres200@gmail.com \\ Universidad Nacional del Comahue, Argentina
}

\section{Resumen:}

Introducción: En esta investigación, se han analizado las categorías "lectura en papel", "lectura en pantalla" y "maneras de leer" a través de la palabra de docentes que pertenecen a diferentes disciplinas y sedes de la Universidad Nacional del Comahue (UNCo), Patagonia, Argentina. Método: Para este estudio, un avance de una investigación mayor realizada en el marco de una tesis doctoral en educación, se ha utilizado el método comparativo constante y se han analizado datos cualitativos provenientes de entrevistas semi-estructuradas a docentes, efectuadas durante el período 2014-2017. Objetivo: El objetivo principal ha sido determinar cuáles son las representaciones de las y los docentes de la UNCo sobre la lectura en pantalla y su relación con la tarea de enseñar en la universidad. Resultados: En cuanto a los resultados, por un lado, se ha observado que las valoraciones sobre la lectura en pantalla se muestran diferentes si el foco es desplazado de la tarea de enseñar a la de investigar. Por otro, se han percibido varios cambios en las formas de leer y de enseñar, aunque se admite que estos no siempre conllevan transformaciones profundas en educación. Conclusión: La prin-

\begin{abstract}
:
Introduction: In this study, the categories "paper reading", "screen reading" and "ways of reading" were analyzed through the words of teachers who belong to different disciplines and headquarters of the Universidad Nacional del Comahue (UNCo), Patagonia, Argentina. Method: For this study, part of a major investigation carried out within the framework of a doctoral thesis in Education, the constant comparative method was used, and qualitative data from semi-structured interviews with teachers, conducted during the 20142017 period, were analyzed. Objective: The main objective was to determine the representations of UNCo lectures regarding screen reading and their relationship with the task of teaching at university. Results: Concerning results, on the one hand, it was observed that the ratings on screen reading were different when the focus was shifted from the task of teaching to research. On the other hand, there were several changes in the ways of reading and teaching, although it was admitted that these do not always lead to profound transformations in education. Conclusion: The main conclusion was that, in certain situations, it seems that the so-called
\end{abstract}

1 Dirección para correspondencia (correspondence address):

María Bernarda Torres. Los Nogales 2521, Neuquén Capital (8300), Argentina. 
cipal conclusión a la que se ha arribado se basa en que, en determinadas situaciones, pareciera que las Ilamadas "nuevas" tecnologías han derribado varios muros, permitiendo una enseñanza más extensiva y abierta, pero al mismo tiempo, se advierte que se han erguido nuevas murallas, algunas de las cuales no hacen más que reproducir viejos modelos pedagógicos.

\section{Palabras clave:}

Lectura; tecnologías; universidad; enseñanza; investigación "new" technologies have demolished several walls, allowing for more extensive and open ways of teaching, but at the same time, it is noted that new walls have been erected, some of which only reproduce old pedagogical models.

\section{Key words:}

Reading; technologies; university; teaching; research

\section{Résumé:}

Introduction: Dans cette recherche, les catégories «lecture sur papier», «lecture sur écran» et «modes de lecture» ont été analysées à travers la parole d'enseignants appartenant à différentes disciplines et sièges de I' Universidad Nacional del Comahue (UNCo ), Patagonie, Argentine. Méthode: Pour cette étude, percée d'une recherche majeure menée dans le cadre d'une thèse de doctorat en éducation, la méthode comparative constante a été utilisée et des données qualitatives issues d'entretiens semistructurés avec des enseignants ont été analysées, menées au cours de la période 2014 -2017. Objectif: L'objectif principal a été de déterminer quelles sont les représentations des enseignants de I'UNCo quant à la lecture sur écran et leur relation avec la tâche d'enseigner à l'université. Résultats: En ce qui concerne les résultats, d'une part, il a été observé que les remarques concernant la lecture sur écran sont différentes si la focalisation est portée sur la tâche d'enseignement ou celle de recherche. D'autre part, plusieurs changements de modes de lecture et d'enseignement ont été perçus, même s'il est admis qu'ils n'impliquent pas toujours de profondes transformations dans I'éducation. Conclusion: La principale conclusion qui a été tirée est basée sur le fait que, dans certaines situations, il semble que les soi-disant «nouvelles» technologies ont démoli plusieurs murs, permettant un enseignement plus étendu et plus ouvert, mais en même temps, notons qu'elles ont érigé de nouveaux murs, dont certains ne font que reproduire d'anciens modèles pédagogiques.

\section{Mots clés:}

Lecture; université; technologies; enseignement; recherche

Fecha de recepción: 22-01-2019

Fecha de aceptación: 17-01-2020 


\section{Introducción}

En el mundo que habitamos en el comienzo del siglo XXI, los muros no son mucho menos sólidos e, indudablemente, no están establecidos de una vez por todas, sino que son eminentemente móviles.

Zygmunt Bauman

Este trabajo ha sido realizado en el marco de la beca "Programa Estratégico de Formación de Recursos Humanos para la Investigación y DesarroIlo (PERHID)" del Consejo Interuniversitario Nacional (CIN), Argentina, 2017, otorgada a docentes universitarios para realizar/finalizar carreras de posgrado (maestrías o doctorados). La carrera de posgrado a finalizar corresponde al Doctorado en Educación que se cursa en la Facultad de Ciencias de la Educación, Universidad Nacional del Comahue. En este artículo, se toma una parte del análisis de datos recolectados entre 2014 y 2017 y, siguiendo el método comparativo constante, se intenta brindar un avance de la investigación. Este estudio ha sido dirigido por la Dra. Carina Lion, de la Universidad Nacional de Buenos Aires, como directora de la tesis, y por la Dra. Teresa Acuña, de la Universidad Nacional del Comahue, como directora de la beca².

\section{Marco teórico}

El primer muro que separa, encierra y algunas veces delata, aunque también conecta a un individuo con el mundo está construido por palabras que, expresadas en un tiempo, espacio y situación determinados, conforman el lenguaje de la comunicación. Existen diversas maneras de pensar y definir el "lenguaje". El concepto de "lenguaje" en los adultos, desde la perspectiva de Vygotsky (1995), constituye la base material del pensamiento. Según Vygotsky (1995), aunque pensamiento y lenguaje formen una unidad dialéctica, en ciertos momentos, entran en contradicción. También estos pueden operar de manera independiente, aun-

2 Cabe aclarar que el articulo corresponde a un avance de la Tesis Doctoral en Educación "Representaciones y concepciones de los docentes universitarios sobre la lectura en pantalla y sus relaciones con los procesos del enseñar: una investigación en la Universidad Nacional del Comahue" Doctoranda: María Bernarda Torres (UNCo) Directora: Dra. Carina Lion (UBA). 
que el pensamiento no puede terminar de integrarse sin el lenguaje. La función primaria del lenguaje es la comunicación, el intercambio social (Vygotsky, 1995, p. 12). Cabe resaltar el papel del lenguaje en la construcción del conocimiento y en la acción emancipadora del ser humano. El lenguaje organiza, construye y transforma el pensamiento, permitiendo que el aprendizaje y la comunicación tengan lugar (Vygotsky, 1995).

Asimismo, el lenguaje es considerado una de las herramientas principales del sistema de representaciones de una sociedad y, por lo tanto, puede pensarse como un reflejo de la sociedad que lo utiliza. A través del estudio del lenguaje de una determinada comunidad, en un contexto histórico y social particular, es posible conocer sus representaciones del mundo (Raiter, Sánchez y Zullo, 2002, citado por Fanese, 2012). La transmisión y el intercambio de representaciones entre las personas se dan al comunicarse los individuos. De esta manera, las representaciones se relacionan, reconstruyen y complejizan, algunas veces se suman a otras, aunque también es posible que se diferencien de su entorno socio-cultural (Fanese, 2012, p. 143). No todas las representaciones individuales pueden convertirse en sociales $y$, del mismo modo, no siempre los individuos comparten todas las representaciones que rigen en su comunidad. Las representaciones sociales compartidas garantizan cierta cohesión social, aunque se desconozcan sus límites (Fanese, 2012). El concepto de representación social que ronda en toda la investigación, si bien proviene de la psicología social (Moscovici, 1981) (Jodelet y Moscovici, 1989), no se limita a esta, sino que tiene en cuenta las reformulaciones realizadas por otros campos del conocimiento, tales como la sociología y la lingüística.

Tras varios años de incorporación de las tecnologías a la vida individual y laboral de los y las docentes universitarios/as, aún se oyen opiniones polarizadas sobre las cualidades y desventajas que provoca la vinculación de la tecnología en las tareas de enseñar y aprender. García Aretio (2007) plantea que los tecnófobos, tenaces defensores de la cultura del libro en papel, responsabilizan a Internet de una decadencia cultural fundada en la idea de que la información y los textos que consultan los y las estudiantes solo responden a leyes del mercado, al consumismo y a la frivolidad. En cambio, para los Ilamados tecnófilos, innovadores entusiastas, Internet ha venido a achicar brechas de distinta índole: distancia, tiempo, posibilidades de acceso a la información, a la innovación. Es sinónimo de democracia que irá poco a poco orientándose a la igualdad, 
a facilitar el acceso a más textos y a mayores oportunidades de vínculos entre las personas.

También están los que se sitúan en una franja intermedia. Este diverso grupo se compone tanto de los que observan y apuestan a transformaciones y cambios que suelen calificar de profundos, ya que revisan y reorganizan viejos pensamientos, como de aquellos que solo utilizan la tecnología de un modo instrumental, siguiendo los mismos patrones con los que se formaron décadas atrás (García Aretio, 2007).

Piscitelli (2004), a partir de las ideas que sostienen tecnófobos y tecnófilos, reflexiona sobre la polarización que se instala en términos de ventajas y desventajas de las nuevas tecnologías y afirma que:

Porque el corazón de la cuestión es aceptar (algo que ni educadores ni mucho menos tecnófilos quieren ni están dispuestos a hacer) que los efectos y las relaciones globales de las tecnologías no pueden entenderse en función de nuestros intereses en materia de medios y fines. Y mucho menos en términos de efectos buenos y malos.

El cambio tecnológico rompe con cualquier esquematismo racionalista y horada todas las divisiones binarias. Porque instala una constelación que abarca lo que se elige y lo que no se elige, lo que se prevé y lo que no puede preverse, lo que se desea y lo que no de desea. (p. 128)

Piscitelli (2004) hace referencia a los riesgos, desafíos y necesidades que instalan las tecnologías en el campo de la educación. En ese sentido, podría pensarse que no solo la manera de leer se ha movido de sus cercos, sino también el acceso a los textos, los formatos, el abordaje de la lectura, la relación entre forma y significado.

La lectura en pantalla suele ser calificada como "lectura nómada, basada en la consulta, secuencial, fraccionada, depredadora, cosmopolita, exploratoria" (Benhamou, 2015, p. 53). Muchos de los adjetivos utilizados para referirse a la lectura en pantalla encierran, en parte, una desvalorización de la calidad de la práctica de la lectura que se traslada al texto, por encontrarse el mismo atrapado tras el cristal de una pantalla. Si bien el texto puede mudarse a otras pantallas de otros dispositivos que se encuentran sincronizados, en todos los casos, el texto y la lectura del mismo resultan fragmentarios. Sin embargo, pareciera que, con el incremento significativo de la oferta de textos científicos, ficcionales y periodísticos, la desconfianza sobre la calidad que genera 
la lectura de un texto publicado solo en un soporte digital estaría perdiendo fuerza.

El cambio constante de soportes para acceder a un mismo o distinto texto (tablets, notebooks, netbooks, smartphones, entre otros) puede comprenderse a partir del concepto de "nomadismo" expresado por Françoise Benhamou (2015). Entre otras cuestiones, Benhamou (2015) trae a consideración la polémica que se genera respecto al grado de liviandad con que se lee un texto desde un soporte digital en comparación al modo analítico con el que se procede cuando el mismo texto está en papel, aseverando que el soporte incide en el modo de leer ya que "el modo de recepción digital transforma el texto a través de tres procedimientos: la indiferenciación, la fragmentación, y la reapropiación" (p. 53). El "nomadismo" de la lectura, según la autora, produce un acostumbramiento por parte del lector al variar, desde una misma pantalla, de un contenido a otro, de un tipo de texto a otro, rompiendo así con las jerarquías de la lectura. Para definir la "indiferenciación", Benhamou (2015) recurre al concepto de equivalencia: "La indiferenciación proviene de esta uniformidad de textos cuyas condiciones de producción, objetivos y razones de ser, son ajenos unos de otros. Entramos así en el reino de la gran equivalencia" (p. 55).

Para Benhamou (2015), "fragmentación" tiene que ver con la idea de que "el pasaje del papel a la pantalla transforma el acto de leer y los modos de apropiación del texto" (p. 55). Llama la atención su observación respecto a una tendencia de llevar la lectura en pantalla a un tipo de lectura secuencial característica del libro en papel. Este horizonte del mundo digital pareciera tener la intención de reparar la "distracción" atribuida y fomentada por el texto en pantalla (Benhamou, 2015, p. 55). La autora destaca los aspectos diferenciales entre la lectura en pantalla y en papel que afectan la percepción y comprensión del texto:

La desorientación cognitiva propia de la lectura digital, es decir, la pérdida del objetivo inicial a través de los enlaces que el lector va encontrando y la dificultad para adaptar el ojo y el cerebro, de manera que el lector, expuesto a una sobrecarga cognitiva, termina perdiéndose. (Benhamou, 2015, p. 56)

Benhamou (2015) considera que la publicación en uno u otro formato exige una emancipación de los fragmentos del texto original, tal como fue pensado, producido y editado. Esa exterioridad influye en la relación 
con el saber ya que, según La Academie des Sciences [Academia Francesa de Ciencias] (2013, citado por Benhamou, 2015), el libro y la pantalla recurren a distintas formas de inteligencia: la del libro está cristalizada y es lineal, lo que propicia la narración y el relato cronológico; y en el caso de las pantallas, la inteligencia es fluida y espacializada, lo que permite revelar y sintetizar información de diversos campos, tipos de textos, fuentes. La alternancia entre ambos tipos de inteligencia permite la lectura a través de un recorrido de páginas con imágenes y texto escrito. Mientras que en la cultura del libro en papel se entabla una relación que se podría llamar "vertical", en la de la pantalla, estaríamos frente a una "relación horizontal". La autora sostiene que "lo digital puede resultar enriquecedor. Fomenta recomposiciones; el lector extrae posiciones selectas para fundirlas en un texto nuevo. La imagen y el sonido ilustran y completan el texto" (2015, p. 57).

Según Michel Foucault (1976), a partir de finales del siglo XVIII comienzan a superponerse dos tipos de tecnologías de poder: las tecnologías disciplinarias (tecnologías individualizantes e individualizadoras, centradas en los cuerpos de los individuos y destinadas a vigilarlos, controlarlos y adiestrarlos con el objeto de hacerlos dóciles y útiles), y las tecnologías reguladoras de la vida (cuyo objeto no sería tanto regular los cuerpos individuales cuanto el cuerpo social, las poblaciones). Ambas se articulan generalmente de tal forma que se esfuerzan optimizando la vida individual y social, maximizando y extrayendo las fuerzas de los individuos y de las colectividades. Estas son consideradas tecnologías que implican la formación de nuevos saberes e instituciones: 1. saberes destinados a jerarquizar, clasificar, vigilar y adiestrar los cuerpos (entre los que se encuentra la ciencia militar, pedagógica, penitenciaria, hospitalaria); 2. saberes destinados a la gestión global de la vida (entre cuyos componentes figura la medicina, la higiene pública, la policía). En este contexto, aparecerá una subjetividad construida por las tecnologías y saberes disciplinarios y la manifestación de un poder opresivo. Esta tecnología (Ilamadas instituciones educativas, cuarteles y fábricas) encuentra en el diseño panóptico de Jeremy Benthan (arquitectura pensada para el sistema carcelario de fines del siglo XVIII, diseñada en forma de " $u$ " o circular, con una torre en el centro para hacerles sentir que, desde allí, en todo momento están siendo vigilados) uno de los dispositivos clave para dirigir las conductas, junto con el espacio de encierro, la reglamentación del tiempo, la fragmentación y división de los individuos, y los 
mecanismos de seguridad colectiva. Un poder que facilita el control de unos pocos sobre muchos (Foucault, 1986).

Paula Sibilia (2012) plantea que, en tiempos de pantallas, pareciera que ya habría necesidad de:

Derribar las paredes, saltar las cercas o escabullirse entre las rejas, ni siquiera gracias a la etérea coartada de los sueños o la imaginación, puesto que las antiguas potencias del confinamiento quedarían desactivadas por las ondas sin cables que lo atravesarán. (p. 192)

De todas maneras, otros autores sostienen que el control y la vigilancia siguen siendo el objetivo del poder dominante. Bauman, por ejemplo, habla de un actual poder sinóptico (en contraposición al panóptico de Foucault) en el que muchos vigilan y controlan a unos pocos. Esta tarea no se limita a la enseñanza, sino que es propia de las redes sociales y persigue distintos fines. En general, a través de ellas y de diversas aplicaciones, como la geolocalización, muchos manejan a pocos con el objetivo de tener incidencia en la vida privada del vigilado (Bauman, 2003).

En relación con la vigilancia en las instituciones educativas, Sibilia opina sobre las mutaciones de los nuevos muros:

Queda claro, aquí, que nuestro drama ha dejado de ser las opresiones del encierro y de la ley, simbolizadas por figuras como las del profesor, el director, el padre, el panóptico, el reglamento [...] y las durísimas paredes que secuestraban rigurosamente el tiempo cotidiano de cada alumno. (2012, p. 192)

Según la autora, el poder no está apoyado en la moral y la ley que rendían culto a la obediencia: "Bastará tan solo con encontrar la manera de burlarlos o esquivarlos, como meros obstáculos que son, para poder consumar todas las posibilidades de la conexión sin las restricciones heredadas de la cosmovisión analógica" (Sibilia, 2012, p. 192). Dice Sibilia (2012):

La subjetividad mediática no se siente amenazada por la alienación del desconocimiento, sino por la sensación de vacío y la desorientación [...] Si el saber o el conocimiento que se transmitía según las reglas pedagógicas tradicionales podía resultar excesivamente sólido y consistente, demasiado 
categórico y tajante en su ambición de representar la verdad, la información adolece de volatilidad y fragmentación. (p. 198)

En cuanto a las revistas científicas en línea, Benhamou (2015) plantea que este tema "parece un espejo con aumento sobre las promesas y peligros de lo digital" (p. 191). En el plano de la investigación, se le concede mayor puntaje a un artículo publicado en una revista académica que en formato libro, aunque este fuera digital; del mismo modo la circulación, acceso y selección es mayor en el caso de los artículos que de los libros. Benhamou (2015) resalta la proliferación de una migración desde la impresión en papel al formato digital, produciendo una diversificación entre fuentes de financiamiento públicas y privadas.

En cuanto a los textos académicos, tomando categorías de JeanFrançois Barbier-Bouvet, Benhamou (2015) afirma que "al hablar de la lectura de revistas, las jóvenes generaciones son 'generaciones bilingües escrito-pantalla'" (p. 57). Benhamou (2015) observa dos aspectos desfavorables sobre los prometedores avances del mundo digital que tienen repercusión en la sociedad:

1. "Si bien lo digital cambia la relación con el libro, no parece acercar a la lectura a aquellos que no tienen el gusto por ella" (p. 58). Es decir que el mensaje "emancipador" sobre las tecnologías ayudaría a achicar la brecha de desigualdad cultural en el mundo gracias al uso masivo de dispositivos digitales no pareciera tener un pronóstico favorable.

2. "La lectura se vuelve una mercancía y el servicio se enriquece alimentándose con datos personales" (p. 59). Siempre se destaca la practicidad de los dispositivos digitales para guardar y transportar grandes volúmenes de textos y la posibilidad que ofrecen de acceder, de una manera sencilla y rápida, a un sinnúmero de bibliotecas, repositorios e información de todo tipo, pero no se resalta con el mismo ahínco que los dispositivos envían información personal, datos de geolocalización a las empresas proveedoras de servicios. Es decir, de la pantalla de los teléfonos celulares, notebooks, netbooks, computadoras, ipads, ipods, no solo se pueden extraer una inmensa cantidad y variedad de datos, sino que todas estas pantallas, continuamente, proporcionan datos. La mayoría de las veces existe el consentimiento de proveerlo, pero no se es consciente de qué tipo de datos son extraídos, con qué propósito, 
quiénes los guardan y qué hacen con ellos, siendo muchos objetos de comercialización y hasta de extorsión.

Si bien lo digital ha estado siempre asociado a la superficialidad y dispersión, Benhamou (2015) destaca su promesa de enriquecimiento a partir de la recomposición y reconstrucción de un texto que surge de la lectura y procesamiento de fragmentos seleccionados. Por otro lado, la posibilidad de acceso tanto a imágenes como a sonidos y la lectura e indagación guiada por los vínculos que un texto propone "rediseña, entonces, la manera de construir y transmitir los saberes" (p. 58).

\section{Marco empírico}

Esta investigación se desprende de una investigación mayor que se está desarrollando en el marco de una tesis doctoral en educación que intenta abordar las representaciones de las y los docentes de la Universidad Nacional del Comahue (UNCo) sobre la lectura en papel y en pantalla, tanto desde lo epistemológico como desde lo didáctico disciplinar.

En este artículo, me he centrado en 10 (diez) entrevistas, de un total de 26 (veintiséis), realizadas entre 2014 y 2017, de las cuales una corresponde a un profesor en Letras (UNCo) y actual estudiante de las carreras Licenciatura en Letras y Tecnicatura Universitaria en Administración de Sistemas y Software Libre, de la UNCo, y las otras nueve a docentes de la mencionada universidad, que se ejercen la docencia en distintas disciplinas y diferentes asentamientos. El objetivo de la investigación consiste en determinar qué representaciones de la lectura en pantalla tienen los y las docentes de la UNCo, de qué manera perciben y valoran la mediación de las tecnologías en la lectura y su injerencia en el proceso de enseñar. Este estudio parte del análisis de las expresiones de las y los docentes y del contexto en el que se desarrollan laboralmente, viven y se comunican.

La investigación ha seguido el método cualitativo de comparación constante. Los datos analizados provienen de fuentes primarias y secundarias. En este artículo, solo se han tomado algunas fuentes primarias, entrevistas semi-estructuradas. Para el análisis, me he focalizado en las referencias a cambios y/o transformaciones producidas en el ámbito educativo, en el modo de leer y/o en la enseñanza, especialmente, cuando 
existe mediación de la tecnología. En la siguiente tabla se muestra mayor información sobre las entrevistas analizadas en este artículo:

Tabla 1

Datos sobre las entrevistas

\begin{tabular}{llll}
\hline $\begin{array}{l}\text { Docente (D)/ estudiante (E) } \\
\text { entrevistado/a }\end{array}$ & $\begin{array}{l}\text { Docente/ } \\
\text { estudiante } \\
\text { citado en } \\
\text { este trabajo }\end{array}$ & $\begin{array}{l}\text { Facultad Ciudad } \\
\text { o sede }\end{array}$ & Año \\
\hline
\end{tabular}

\begin{tabular}{lllll}
\hline 1. D. Facultad de Lenguas $1 \quad \sqrt{ } \quad$ FATU Neuquén Cap. & 2014
\end{tabular} (D. FadeL 1)

\begin{tabular}{llll}
\hline 2. D. FadeL 2 & FACE & Cipolletti & 2014 \\
\hline $\begin{array}{l}\text { 3. D. Facultad de Ingeniería 1 } \\
\text { (D. FAIN 1) }\end{array}$ & FAIN & Neuquén Cap. & 2014 \\
\hline
\end{tabular}

\begin{tabular}{lllll}
\hline 4. D. FadeL 3 & $\sqrt{ }$ & FAI & Neuquén Cap. & 2015 \\
\hline 5. D. Facultad de Ciencias de & & FACE & Cipolletti & 2015
\end{tabular} la Educación 1 (D. FACE 1)

\begin{tabular}{llll}
\hline 6. D. FAIN 2 & $\sqrt{ }$ FAIN & Neuquén Cap. 2015 \\
\hline 7. D. Faculat
\end{tabular}

7. D. Facultad de Ciencias del $\quad$ FACIAS Neuquén Cap. 2015 Ambiente y la Salud (D. FACIAS)

8. D. Facultad de Derecho FADECS Neuquén Cap. 2015 y Ciencias Sociales 1 (D. FADECS 1)

\begin{tabular}{|c|c|c|c|c|}
\hline 9. D. FACE 2 & & $\mathrm{FaHu}$ & Neuquén Cap. & 2015 \\
\hline $\begin{array}{l}\text { 10. D. Facultad de Informática } \\
\text { (FAI) }\end{array}$ & & FAI & Neuquén Cap. & 2015 \\
\hline $\begin{array}{l}\text { 11. D. Facultad de Humanida- } \\
\text { des (FaHu) }\end{array}$ & $\sqrt{ }$ & $\mathrm{FaHu}$ & Neuquén Cap. & 2015 \\
\hline $\begin{array}{l}\text { 12. D. Centro Universitario } \\
\text { Regional Zona Atlántica } \\
\text { (CURZA) } 1\end{array}$ & & CURZA & Viedma & 2016 \\
\hline 13.D. CURZA 2 & & CURZA & Viedma & 2016 \\
\hline 14.D. CURZA 3 & & CURZA & $\begin{array}{l}\text { Viedma y San } \\
\text { Antonio Oeste }\end{array}$ & 2016 \\
\hline $\begin{array}{l}\text { 15. D. Facultad de Economía y } \\
\text { Administración (FaEA) }\end{array}$ & $\sqrt{ }$ & $\begin{array}{l}\text { AUZa y } \\
\text { FaEA }\end{array}$ & $\begin{array}{l}\text { Zapala y Neu- } \\
\text { quén Cap. }\end{array}$ & 2017 \\
\hline $\begin{array}{l}\text { 16. D. Centro Regional Univer- } \\
\text { sitario Bariloche (CRUB) } 1\end{array}$ & & CRUB & $\begin{array}{l}\text { San Carlos de } \\
\text { Bariloche }\end{array}$ & 2017 \\
\hline $\begin{array}{l}\text { 17. D. Facultad de Ciencias } \\
\text { Agrarias (FaCA) }\end{array}$ & $\sqrt{ }$ & FaCA & Cinco Saltos & 2017 \\
\hline
\end{tabular}




\begin{tabular}{|c|c|c|c|c|}
\hline $\begin{array}{l}\text { Docente (D)/ estudiante (E) } \\
\text { entrevistado/a }\end{array}$ & $\begin{array}{l}\text { Docente/ } \\
\text { estudiante } \\
\text { citado en } \\
\text { este trabajo }\end{array}$ & $\begin{array}{l}\text { Facultad } \\
\text { o sede }\end{array}$ & Ciudad & Año \\
\hline 18. D. FadeL 4 & & AUSMA & $\begin{array}{l}\text { San Martín de } \\
\text { los Andes }\end{array}$ & 2017 \\
\hline $\begin{array}{l}\text { 19. D. Facultad de Ciencias } \\
\text { Médicas (FACIMED) }\end{array}$ & & $\begin{array}{l}\text { FACl- } \\
\text { MED }\end{array}$ & Cipolletti & 2017 \\
\hline 20.E. FACE 1 y 2 & & FACE & Cipolletti & 2017 \\
\hline 21.D. CRUB 2 & & CRUB & $\begin{array}{l}\text { San Carlos de } \\
\text { Bariloche }\end{array}$ & 2017 \\
\hline 22.D. FADECS 2 & $\sqrt{ }$ & FADECS & General Roca & 2017 \\
\hline $\begin{array}{l}\text { 23.D. Escuela Superior de } \\
\text { Ciencias Marinas (ESCM) }\end{array}$ & & ESCM & $\begin{array}{l}\text { San Antonio } \\
\text { Oeste }\end{array}$ & 2017 \\
\hline 24.E. 3 FAl y FaHu & $\sqrt{ }$ & $\begin{array}{l}\text { FAl y } \\
\text { FaHu }\end{array}$ & $\begin{array}{l}\text { Neuquén } \\
\text { Capital }\end{array}$ & 2017 \\
\hline $\begin{array}{l}\text { 25.D. Facultad de Ciencias y } \\
\text { Tecnologías de los Alimen- } \\
\text { tos (FACTA) }\end{array}$ & $\sqrt{ }$ & FACTA & Villa Regina & 2017 \\
\hline $\begin{array}{l}\text { 26.D. Facultad de Turismo } \\
\text { (FATU) }\end{array}$ & & FATU & $\begin{array}{l}\text { Neuquén } \\
\text { Capital }\end{array}$ & 2017 \\
\hline
\end{tabular}

\section{Resultados y discusión}

La relación lectura-enseñanza y lectura-aprendizaje son temas que siempre han sido indagados por los docentes e investigadores de la educación. Actualmente, se han revisado ciertos conceptos a partir de las relaciones textos-soportes, soportes-lectores, tecnología-enseñanza, tecnología-aprendizaje, entre otras. Los y las docentes de UNCo que participaron en esta investigación, recurrentemente, usan expresiones que remiten a cambios de comportamientos íntimamente relacionados a la irrupción de las tecnologías en todos los ámbitos de la vida y, por ende, también en las aulas universitarias. Esas referencias, que oscilan desde una mirada positiva a otra poco alentadora, con respecto a las prácticas de lectura en papel y en pantalla, también dejan sobre la superficie diferentes modos de pensar la enseñanza. Por ejemplo, un docente del área de las Ciencias Sociales refiere a cambios en los modos de leer y lo atribuye a modificaciones en el entorno, a las diferentes posibilidades de portabilidad e intervención. Desde su experiencia como investigador de 
la comunicación, este docente resalta una idea de migración al mundo digital:

Bueno la lectura cambió. La pantalla es una verdadera revolución en las formas de lectura. No lo digo yo, "lo dicen". Ciertamente, es una revolución porque cambió los modos de leer, porque son otro entorno, porque tiene cuestiones de portabilidad que permite la intervención en los textos más directa. Y esa pantalla es otra forma de lectura que genera otros hábitos y conforma otros sistemas que se llama retroalimentación. [...]Yo no podría decirte si la lectura de libros es mayor o menor que años atrás, pero sí sé que se lee mucho, en distintos dispositivos, en los teléfonos celulares, en las tabletas, en las computadoras portátiles, en las computadoras fijas. [...] hay más puestos de lectura y cambia la forma de lectura porque quizás la pantalla es un poco más agresiva a la vista $[\ldots]$. O sea, se leen textos más cortos, o textos más aireados, pero también lo que permitió la digitalización es que esas lecturas sean con mayor profundidad. (D. FADECS 2, 2017)

Al mismo tiempo que este docente trata de comprender qué les sucede a los que crecieron en la era digital, en sus expresiones se percibe una capitalización positiva de las posibilidades que ofrece el formato digital:

Yo tengo 53 años. Teníamos lecturas que venían guiando, en el libro, un orden secuencial, lectura de textos, a veces, algunas fotos y ahora estamos con una "metástasis" de códigos donde vos tenés esta posibilidad de armar el texto, de consumir distintos códigos. Siento que leo los textos y, si están los videos, leo los videos, leo los audios y para mí conforman ese mensaje. Mi estrategia lectora es otra, es completamente distinta, es mucho más divertida este tipo de lectura, aun cuando soy un gran lector, pero yo no soy la media. (D. FACDECS 2, 2017)

A través del lenguaje, se visualiza una posición abierta hacia la indagación en el campo digital que, sin desechar la lectura en formato papel, sino aceptando una manera de leer distinta, completa, se suma o recrea la ya existente.

Otras opiniones enaltecen los atributos de las tecnologías, poniendo énfasis en los cambios sustanciales en la vida cotidiana. Un estudiante de las carreras Licenciatura en Letras y Tecnicatura en Software Libre 
manifiesta que el avance tecnológico ha superado lo imaginable, ya sea en educación como en el arte de las letras:

¡Cosas que antes ni te imaginabas! Tener en el bolsillo 200 títulos y leerlos cuando quieras, que es impensado andar con 200 libros encima. Es una cuestión del espacio físico que ha cambiado, gracias a la tecnología en sí. También me parece que la nueva literatura se está cruzando con lo que es el discurso o el registro, si se quiere, de las redes sociales. Por ejemplo, en algunas novelas aparecen mensajes de texto, o aparece el tema de la informática, también muy presente, de cómo eso influye, tal vez, en la vida de los personajes y se va metiendo por distintos lugares, desde cómo lo leemos hasta las mismas historias que tal vez se presentan desde la ficción. (E. FAHU y FAl, 2017)

Este estudiante reflexiona sobre las transformaciones que han sucedido a partir de la acción y la mediación de la tecnología en la vida de las personas, produciendo cambios tanto a nivel socio-comunicacional como cognitivo-individual:

Yo creo que a nivel cognitivo debe haber algo ahí que cambia. Hay algo que cambia al tener algo físico como el papel que lo podés doblar, lo podés arrugar, lo podés rayar, a tener algo virtual que te aparece en una pantalla y te desaparece. Yo creo que implica algo que no lo podría explicar, porque si no, lo hubiera estudiado, no lo he indagado. Pero yo sí creo que nuestro cerebro responde diferente a eso. No es lo mismo una pantalla que algo físico, no es lo mismo que estemos hablando, nosotros ahora, así, en este lugar y en este momento, a que vos estés en tu casa y estés hablando por Skype y nos veamos igualmente. Hay algo que cambia en la relación entre persona y soportes, que no te sabría explicar, pero sí me parece que es distinto, no sucede lo mismo. (E. FAHU y FAI, 2017)

Según una docente, la desorientación y dispersión en la lectura que se observa en las y los estudiantes son propiciadas por el soporte pantaIla. Lo que por un lado se considera una potencialidad, como es el caso de la rapidez o mayores posibilidades de acceso a numerosos textos, por el otro, se percibe como un riesgo: 
Y las lecturas cambiaron. Del papel cambió a la computadora, a la lectura digital, digamos. Y es distinto. El papel te daba más tiempo, era como que te daba más tiempo para madurar las cosas. Lo digital, la lectura digital es como que es más rápida. Tenés mucha más información, toda junta. Con los hipervínculos vos podés empezar leyendo una cosa y te vas por otra. Te vas por las ramas. Eso es con lo que hay que tener cuidado a veces con los alumnos, cuando uno los manda a leer algo. (D. FadeL 1, 2014)

Un mismo texto que se pasa del papel al formato digital, se fragmenta en la práctica de la lectura. El lector digital se nutre de varios textos abiertos simultáneamente, haciendo prevalecer el extracto por sobre la unidad textual. Así como Platón, al dejar testimonio de la sabiduría de su maestro Sócrates, muestra en sus escritos "cómo este rechaza la escritura por ser demasiado estática, demasiado fija —en comparación con la vivacidad del argumento hablado- para expresar la verdad" (Meek, 2004), cuando los y las docentes se refieren a los textos digitales, también expresan ciertos valores que cambian o se pierden, generando cierto rechazo:

1. Pérdida de paciencia: "Bueno la cuestión informática cambió mucho el tema de cómo uno encara la lectura, yo creo que se ha perdido paciencia para leer desde que es todo digital, con tantas cosas digitales" (D. FAIN 2, 2015).

2. Pérdida de concentración:

Yo notaba que cuando leían a través de los libros de texto, en papel, la concentración era mayor, como que toda la energía estaba puesta en la lectura. En cambio, con la pantalla, es como que uno se dispersa un poquitito. Está en esto, pero a su vez en otras situaciones. Sí, es por el formato de pantalla que uno puede realizar varias tareas al mismo tiempo, entonces, como que uno no está totalmente metido en ese tema del mismo modo que si estuviera leyendo un texto en papel. (D. FACTA, 2017)

3. Pérdida de esfuerzo: "Esfuerzo, ahí todo lo que sea lectura hay un trabajo y está vinculado con esto. Yo noto que en los chicos de ahora que les cuesta mucho esto, que es un valor que no está presente: el esfuerzo, el trabajo, la constancia para el estudio ¿no?" (D. FACTA, 2017). 
En estos fragmentos, las palabras "paciencia", "concentración" y "esfuerzo" señalan condiciones que favorecen el aprendizaje y que, en caso de estar ausentes, pueden convertirse en un obstáculo en la tarea de enseñar. Cabe tener en cuenta que, desde el 2014 a la actualidad, los avances mundiales en tecnología, especialmente en lo referente a telefonía celular, han sido significativos, así como las mejoras en la infraestructura de la UNCo, lo cual lleva a considerar que estas expresiones citadas, pronunciadas en determinado momento por estos docentes hoy podrían ser distintas. Esto condice y responde, en cierto modo, a la particularidad de la época, por algunos llamada post-modernidad ${ }^{3}$, por otros "modernidad líquida"4 (Bauman, 2003), la cual se destaca por la fluidez, flexibilidad y constante adaptación a nuevos moldes o modelos. El testimonio de una docente sirve como ilustración de cómo la firmeza de un pensamiento puede volverse elástica hasta causar una sensación de alienación:

Diez años atrás, no se me hubiera ocurrido nunca leer un libro en Internet. Es más, usaba muy poco la máquina. Es más, yo decía que a la máquina no la iba a usar nunca. No sé si son diez o quince. Suponete que quince. Te puedo decir más, una anécdota. Rápido te lo cuento. [...] Juntarnos con los compañeros del colegio porque eran los veinte años de egresados. $Y$ todos se pasaban los mails. Y yo no tomé ninguno, porque yo digo: "Eso no voy a tener nunca." $Y$ después, empecé, con los años, a decir: ¡¿Cómo no tomé los mails?! (D. FadeL 1, 2014)

En cuanto a la reapropiación, el docente de FADECS muestra cierta sintonía con esta idea de que el mundo digital permite enriquecer la experiencia de lectura a través de una conexión directa a otras fuentes (textos, mapas, videos):

La posibilidad o el potencial que tiene el soporte de la web de ofrecernos los hipervínculos nos impone una lectura hipertextual todo el tiempo, de

3 El término "post-modernidad" se popularizó con la publicación de La condición posmoderna (1979), de Jean-François Lyotard, pero varios autores ya lo habían empleado anteriormente.

4 El concepto de "modernidad líquida", acuñado por Zygmunt Bauman, intenta caracterizar los comportamientos de la sociedad actual, en contraposición a las generaciones anteriores, para las cuales los valores y dogmas eran más fijos y estables, como lo es la materia sólida (Bauman, 2003). 
grandes hipertextos. La web es un hipertexto. Y me parece que también se va generando, se va imponiendo una costumbre de leer estos hipertextos donde vas armando tus caminos, buscando enlaces que te lleven a otras informaciones contextuales. Ampliar para tener más datos. Con estas herramientas de otro tipo, el código textual deja de ser el predominante, aun cuando puede ser el código que todavía sigue guiando la lectura. Sigue siendo principal y o referente de la lectura. Lo que empieza a aparecer son otros códigos que generan mucha más atracción: el video, las tipografías, las líneas del tiempo, mapas; aparecen un montón de otros códigos que se van conjugando en el armado de un mensaje. La lectura no es solo textual, si no que empieza a ver otro tipo de lectura, obviamente otras estrategias de la lectura, que son distintas. (D. FaDECS 2, 2017)

Aunque en la actualidad, muchas instituciones conservan el diseño arquitectónico panóptico, con muros de ladrillos que dividen y cercan los lugares de encierro, en forma simultánea, también cuentan con aulas virtuales, administradas desde una plataforma virtual, en el caso de la UNCo, la Plataforma de Educación del Comahue (PEDCo). Asimismo, es frecuente el uso de las redes sociales que permiten crear grupos cerrados que facilitan el intercambio comunicacional entre docentes y estudiantes. En todos los casos, el poder opresivo puede o no estar presente. Si bien las tecnologías digitales están libres de obstáculos materiales, como el espacio y tiempo sincrónicos, facilitando el fluir de la comunicación e información, esto no significa que, necesariamente, el modelo de enseñanza haya atravesado una transformación profunda.

Las experiencias de enseñanza mediada por tecnología se están expandiendo y, en el caso de la educación superior, parecen tener buenos resultados, aunque cierta desconfianza sigue estando presente. Esto se debe a que el perfil del estudiante universitario es "capaz de trazar su carrera en torno a proyectos individuales para diferenciarse y vencer a los demás, algo casi opuesto a la vocación integradora y homogeneizante esgrimida por el antiguo dispositivo pedagógico" (Sibilia, 2012, p. 195). Uno de los docentes cuenta su experiencia positiva durante el cursado de una maestría a partir de la apropiación de saberes que desea socializar en su tarea docente:

Antes sí me resultaba muy tedioso, pero porque no sabía. Entonces entraba en el Internet general y, viste que te cruzás con miles de cosas. Yo no sabía 
que existía el google académico, por ejemplo. Eso lo aprendí en la maestría. Yo me sentía un ignorante total y ahí viste que el google académico te limpia un montón. Y bueno, sí, después entrás, así que tenés posibilidad de acceder a la Biblioteca de Ciencia y Técnica y bueno, ahí ya buscás pero buscás todo dentro de los artículos científicos. Si no lo otro tenés que tener mucho cuidado porque son artículos en general. [...] Y yo por ejemplo se los trato de transmitir porque yo creo que no lo saben. De hecho, buscan por cualquier lado. (D. FACA, 2017)

Otros también destacan la influencia positiva de las tecnologías en el aprendizaje:

No hace falta ir a la biblioteca a leer. Hoy los libros están en la compu. Eso sí se aprovecha. Pero se busca más el material interactivo. Uno de los materiales que estamos defendiendo son los videitos, que sí se miran y se "googlean" mucho. Ya no se va a buscar algo. No se lee medio libro para buscar el tema. Ahora se tiene el tema y se lo busca en google. Primero se tiene el problema, después se va a buscar la solución. En cambio, nosotros leíamos en función de los problemas que iban a aparecer. Conocer las técnicas estadísticas para resolver los problemas. Ahora ven el problema y van a buscar la técnica. (D. FaEA, 2017)

Yo creo que estamos en la sociedad de la imagen hoy. Creo que entra mucho por lo auditivo y por lo visual. Yo creo que complementa al estudio, al aprendizaje, o sea, ayuda al aprendizaje. Es un complemento para eso. (D.

FadeL 3, 2015)

En las entrevistas, una de las docentes hace hincapié en el uso de datos disponibles en la red, como fuente de estudio de la realidad. Resalta que uno de los cambios valiosos que ha derivado de la irrupción de la tecnología digital y del uso masivo de Internet en el campo de la investigación es el uso de los datos subidos a la red que registran distintos aconteceres de la realidad sin la necesidad de estar presente en el escenario:

Y yo ahora estoy fascinada, porque nosotros estamos estudiando hace años "oposición" en la legislatura, en la provincia, en la "muni", entonces, hay

5 Se usa "muni" para hacer referencia a la municipalidad o municipio. 
como mucho dato empírico que supera la particularidad; o lo inédito del dato supera las lecturas que están a mano. Digamos, esta división tan fuerte en la votación, por ejemplo, que ganan unos pierden los otros, pierden acá, pero ganan en este escenario, como un cruzamiento de cosas, lo que nos permite la investigación es teorizar y generar nosotras nuestro propio marco teórico, pero teniendo como referencia a otros autores. Están siendo como motivadores de escenarios actuales, para la búsqueda. Hay cosas que suceden en la realidad que te motiva la búsqueda, que te desafía a ir: "Mirá encontré esto, aquello". (D. FADECS 1, 2015)

Otro docente, a pesar de declararse reticente al uso de la tecnología aplicada a la enseñanza (el único entrevistado que no usa la plataforma educativa ni los grupos en redes sociales en sus cátedras), reconoce las ventajas que ofrecen las revistas en línea en caso de estar alejados de las grandes librerías:

Internet lo que ofrece de bueno para la filosofía son artículos de revistas. Antes uno tenía que subscribirse, mandar el giro en dólares o euros. Era muy difícil estar actualizado. En cambio, ahora, la gran mayoría de las revistas están en internet y uno puede encontrar buenos artículos en inglés, francés o castellano. Entonces para eso si viene bien el uso de internet. (D. $\mathrm{FaHu}, 2015)$

Sin embargo, a pesar de todas las ventajas que presenta la enseñanza "virtual" o la llamada "semipresencial" respecto a la independencia y autonomía que le otorgan las herramientas digitales al estudiante, existe un muro invisible, difícil de sortear: la volatilidad, la condición de evanescencia de la información. Es decir, la instantaneidad desarma todo lo aprendido, los valores incorporados y conlleva a un terreno incierto, con nuevas y desconocidas reglas de juego (Bauman, 2003). Aunque desprovistas de paredes divisorias, fuera de los lugares de encierro y sin ataduras al tiempo, las aulas virtuales deben enfrentarse a nuevos muros, resistentes y difíciles de franquear: la invisibilidad frente a la multitud de artículos, revistas y documentos de todo tipo que alojan las bases datos y repositorios; y la fragmentación y volatilidad de la información. 


\section{A modo de conclusión}

A partir de la palabra de las y los docentes de la UNCo, es posible afirmar que los cambios observados en la enseñanza universitaria, surgidos a partir de la incorporación de las tecnologías en diversas actividades académicas, han sido significativos, dando lugar a una enseñanza más extensiva y abierta, pero, al mismo tiempo, las y los docentes advierten el surgimiento de ciertos riesgos. La lectura en pantalla y otras prácticas mediadas por tecnologías han logrado derribar varios obstáculos, aunque otros cercos se han eregido, algunos de las cuales no sólo impiden viabilizar los cambios y transformaciones esperados, sino que reproducen viejos modelos pedagógicos.

En relación con el epígrafe de este artículo, es posible pensar que los muros del mundo digital presentes en las instituciones educativas del siglo XXI responden a principios que rigen nuestra sociedad líquida (Bauman, 2003). En la era digital, la rigidez de los muros no pasa por la condición de ser estáticos, sino que, aún siendo movibles y adaptables, y muchas veces intangibles e invisibles, pueden resultar extremadamente inflexibles. Aunque no interpongan un ladrillo, una puerta, un papel o un uniforme, representan nuevos riesgos e impedimentos en políticas de acceso, circulación y selección de la información.

Una metáfora de Richard Sennet (2009) quizás ayude a explicar mejor de qué manera la enseñanza universitaria, desde la mirada de las y los docentes de la UNCo, se ve implicada en una transformación más o menos profunda o hasta qué punto las pantallas en educación eventualmente representan destellos decorativos que favorecen la perpetuación de estereotipos arcaicos. Sennet (2009) nos invita a imaginar que estamos en un vagón de un tren detenido, mirando por la ventanilla. De repente, vemos partir el tren del andén contiguo. Por unos instantes, tenemos la sensación de que es nuestro tren el que ha empezado a moverse. En realidad, esa sensación es solo una ilusión óptica. El entorno se mueve, aparece y desaparece: "y es nuestro propio yo el que creemos que está fuera del torbellino como el único punto estable en medio de un mundo volátil" (Sennett, 2009). Las y los docentes de la UNCo se reconocen en medio de un torbellino de cambios e, independientemente del campo de estudio al que pertenezcan y de las capacitaciones que la institución les haya ofrecido, todos/as se preparan o inician la marcha, aunque no necesariamente elijan el mismo tren. 


\section{Referencias}

Bauman, Z. (2003). Modernidad líquida. Buenos Aires: Fondo de cultura económica. Benhamou, F. (2015). El libro en la era digital. Buenos Aires, Barcelona, México: Paidós. Fanese, G. (2012). Escritura fugitiva. Ensayo y política de género. Minelli, M. y Fanese, G. (Eds.) Representaciones y sujet*s. Discursos sociales y expresiones estéticas, (pp. 139-165). Córdoba, Argentina: Alción.

Foucault, M. (1986). Vigilar y castigar: nacimiento de la prisión. Madrid: Siglo XXI Editores.

García Aretio, L. (abril de 2007). Los docentes: Entre tecnófilos y tecnófobos. Obtenido de Boletín Electrónico de Noticias de Educación a Distancia (BENED). Editorial del BENED: https://www2.uned.es/catedraunesco-ead/pub_Garcia.htm

García, J. A. (enero-junio de 2016). La lectura digital y la formación del lector digital en España: la actividad de la Fundación Germán Sánchez Ruipérez y el Proyecto Territorio Ebook. Álabe, 13, 207-231.

Jodelet, D., y Moscovici, S. (1989). Folies et représentations sociales. Paris: Presses universitaires de France. Paris: Presses universitaires de France.

La Academie des Sciences. (2013). Lénfant et les ecrans. París: Le Pommier.

Meek, M. (2004). En torno a la cultura escrita. México: Fondo de Cultura Económica.

Moscovici, S. (1981). Representaciones sociales. Madrid: Universidad Complutense de Madrid.

Piscitelli, A. (2004). Tecnologías educativas: una letanía sin ton ni son. Signo y pensamiento, 23(44), 53-61.

Raiter, A., Sánchez, K. y Zullo, J. (2002). Representaciones sociales. Buenos Aires: Eudeba.

Sennett, R. (2009). El artesano. (M. A. Galmarini, Trad.) Barcelona: Editorial Anagrama.

Sibilia, P. (2012). ¿Redes o paredes? La escuela en tiempos de dispersión. Ciudad Autónoma de Buenos Aires: Tinta Fresca.

UNCo. (30 de octubre de 2018). Secretaría académica. Unidades académicas. Obtenido de http://www.uncoma.edu.ar/index.php/unidades-academicas/

Vygotsky, L. S. (1995). Pensamiento y lenguaje: teoría del desarrollo cultural de las funciones psíquicas. Buenos Aires: Fausto. 
